\title{
Impossible Standards and Unlikely Trade-Offs: Can Fathers be Competent Parents and Professionals?
}

\author{
Jamie J. Ladge and Beth K. Humberd
}

This is the worst period in history to be a dad.

- Adam Carolla, in his book Daddy Stop Talking (2016).

The topic of fatherhood has garnered increased scholarly attention over the past several decades. Initially limited primarily to sociology, developmental psychology, and the humanities (Lamb 2004), management scholars are now focused on understanding fatherhood given the rise in dual career couples (e.g., Masterson and Hoobler 2015; Shockley and Allen 2018), and the availability of family friendly organizational policies (Allen 2001; Kossek and Lautsch 2018). Where prior literature recognized the important role that fathers play in the psychological wellbeing of their children (Yeung et al. 2001), the family unit (Lamb 2004; Yeung et al. 2001), and society as a whole (Dowd 2003), management literature considers the impact of fatherhood, and in particular, "involved fathers" - those who are more engaged, accessible and nurturing in their children's lives - in the workplace. Research finds that when fathers are more involved with their children, they may experience increased job satisfaction, greater work-family enrichment and lower work-family conflict (Ladge et al. 2015). However, they may also face a backlash if involved fathering detracts from perceptions that they are ideal workers that can be fully present and devoted to work above all else (Coltrane et al. 2013; Williams et al. 2013; Rudman and Mescher 2013).

While fathers today are becoming more involved at home than in prior generations, scholars question just how "involved" involved fathering truly is (Wall and Arnold 2007), and the extent to which workplace and societal norms may limit a

\footnotetext{
J. J. Ladge $(\bowtie)$

D’Amore-McKim School of Business, Northeastern University, Boston, MA, USA

University of Exeter Business School, Exeter, UK

e-mail: j.ladge@northeastern.edu

B. K. Humberd

Manning School of Business, University of Massachusetts Lowell, Lowell, MA, USA

e-mail: beth_humberd@uml.edu
} 
father's ability to actually enact such involvement (Williams et al. 2016). When men take their involvement in their child(ren)'s lives "too far," they may personally feel they are out of their comfort zone or may put others out of their comfort zone, particularly in contexts where traditional views of fatherhood (e.g., as household provider) persist. As the opening quote suggests, this could be considered "the worst" time to be a dad because now there is an expectation that fathers will not only be competent and committed professionals, but also competent and committed parents.

Comedian and author of Daddy, Stop Talking, Adam Carolla further lamented in an interview with Men's Health Magazine, "A certain amount of interaction between a father and his kids is necessary. . .but. . .it's not about logging the minutes you're spending with your kids...My kids, here's what they need. They need a lot of interaction with their mommy. And they need some interaction with their daddy. But mainly, they need to respect their dad. They need to say, 'I don't see my dad as much as I see my mom, but that's okay because my dad busts his tail for this family." While Carolla's sentiments are certainly not reflective of all dads' perspectives, in our own research of working fathers, we noted some implicit protests around the expectations facing dads today (Humberd et al. 2015; Ladge et al. 2015). One research participant, who was a relatively new father, admitted that he was surprised and even annoyed by his high level of involvement with his child relative to his spouse. Such views may be a reflection of outdated gender norms, or they could suggest that we are creating impossible standards for fathers, similar to those that have long plagued working mothers.

Many questions remain with respect to what it actually means to be an involved father today and the ways in which organizations can encourage a more holistic view of men as ideal parents and professionals. In this chapter, we reflect on these considerations by drawing from prior research and set an agenda for further examining fatherhood in an organizational context.

\section{Traditional Notions of the Ideal Father in Work and Family Contexts}

Idealized views of fatherhood have been characterized by a "deep-seated ambivalence" since the early 1800s (Pleck 1997:351, as cited in Burnett et al. 2011). Traditionally, an ideal father was a man viewed as the primary breadwinner (O'Brien and Shemilt 2003). While mothers were expected to intensely focus on children, fathers were expected to focus solely on work. In this traditional sense, the notion of an ideal father coincides with the notion of an ideal worker - someone who is fully devoted to one's organization taking little time for himself or family (Reid 2015; Williams 2001). To be an ideal worker, a father's primary responsibility to the family can only be to provide financial support with minimal caregiving expectations. Fathers who did engage in more childcare responsibilities than expected or 
take time off for paternity leave might be seen as weak or "liberal sissy men" because "a real man works" (Weber 2013). While these views are largely seen as outdated, they continue to persist in depictions of fathers on television, in movies, and in the popular press, which emphasize the father as the sole provider of the family, who is often portrayed as a lazy, irresponsible, incompetent "part-time" parent (Nathanson and Young 2006; Wall and Arnold 2007).

Traditional expectations of fatherhood exist in response to masculine cultural norms tied to workplace norms that stipulate less involvement with family and more time in the office for men in particular (Cooper 2000; Coltrane 1997). A good dad, in the traditional sense, was someone who simply showed up to school events and engaged in few other childcare activities (Hochschild 1989), given his primary site of engagement was the workplace. Research finds that fathers receive a "fatherhood premium" at work, garnering higher earnings than childless men, because having children signals they have a family to support (e.g., Hodges and Budig 2010; Killewald 2013). Due to traditional beliefs that a father's central role is to provide for his growing family, Dahl and colleagues suggest that male executives may "have an impulse to husband his firm's resources for himself and his growing family, potentially at the expense of his employees by reducing their wages or increasing them less than he otherwise would have done" (Dahl et al. 2012:672). This research found that when male CEOs have children of their own, they pay themselves more, particularly when fathering a son; they also pay their employees "less generously" even more so when they have a daughter first rather than a son (Dahl et al. 2012). Thus, the transition to fatherhood influences men's own values in ways that may reinforce traditional notions of fatherhood, and these reinforced views can have unintended organizational impacts.

On the home front, traditional notions of fatherhood are also reinforced by feminine norms and gender ideologies, which often determine paternal involvement (Bulanda 2004). In the United States, individuals are socialized to believe that men and women are associated with particular roles in the household, with women engaging in more of the housework and childcare activities than men (Coltrane and Ishii-Kuntz 1992). Even in couples with more egalitarian views, research suggests that after the birth of their first child, many couples tend to fall back on traditional gender roles (Coontz 1997). Similarly, in the most egalitarian societies where paternity leave is widely available and encouraged (e.g., Nordic countries), women still take substantially more time off after childbirth (OECD 2017). Research suggests that when men do engage in a high degree of parental involvement, it can lead some women to prevent their husband's involvement because it violates the perception that a woman's primary domain is in the home (e.g., Allen and Hawkins 1999). As Bulanda (2004:40) notes, "it may be that the gender ideology of a traditional wife leads to a lack of reinforcing behavior for a less traditional husband who attempts to become more involved with his children. Her belief that a man is not capable of nurturing or caring for children may lead her to limit the amount of her husband's involvement." Even when mothers welcome their spouses's involvement, they may still believe that it infringes on their primary role or they may think that fathers do not have the skillset or ability to nurture their chidren (Allen and Hawkins 
1999). Additionally, mothers are often shamed when they do not provide the primary care for their children (Cain Miller 2018). Together, these reinforcing dynamics make traditional notions of fathering - tied to work and masculinity - difficult to change.

\section{Contemporary Fathers in Work and Family Contexts}

"I'm a dad, not a hero. I'm also not babysitting them. I'm their dad." - Peter Mountford.

Despite the cementing of traditional notions of fathering in societal and organizational contexts, recent scholarship explores the changing role of the father. Some suggest as a result of the Great Depression, men may have begun to be seen as poor, ill-fated providers (Lamb 2004), encouraging them to become more active, involved and nurturing parents (Griswold 1993; Pleck 2004). Further, the changing nature of family structures and increases in the number of dual career couples necessitated a multidimensional view of a father's role, beyond simply a provider but also that of caregiver, role model/teacher, and protector (Lamb 2004). Researchers have documented the "modern" father from Western conceptualizations, where views have shifted from the father as the sole breadwinner and provider towards an idealized view of fathers as more involved in caregiving and emotionally present for their children (Burnett et al. 2011; Cabrera et al. 2000). The "involved father" is one who "should be flexible enough to both earn a wage and be able to help fix dinner and read a bedside story" (Burnett et al. 2011:164). In many ways, this new dad is beholden to similar expectations facing working mothers.

\subsection{The Upside of Involved Fathering}

Ensuing narratives suggest that the "involved father" benefits not only their children, but also their spouse and themselves. Greater paternal involvement may be a positive contributing factor to children's educational attainment, adolescent behavior, and overall psychological well-being (Furstenberg Jr. and Harris 1993; Marsiglio et al. 2000). More involvement can also have positive impacts on the family's overall well-being (Glass 1998), particularly when shared caregiving alleviates the burden experienced by many working mothers (Hochschild 1989). When fathers are active caregivers, they create a more equitable household (Coontz 2009, 2016) where children benefit from having two parents they can equally connect with (Deutsch 1999) and each partner feels less stressed, less guilty, and less career impact from family strains (Holcomb 2000). There are also intrinsic benefits for fathers when they are directly involved with their own children (Deutsch et al. 1993). Anecdotal experiences of fathers reflect such benefits: On a fathers blog, James Norton notes, "Speaking personally, I like changing diapers. Let me restate that: I take satisfaction 
in changing diapers. Since breastfeeding isn't an option, it's an aspect of childcare where my own limited talents can contribute, if not actually shine. I like the postdiaper smiles. And I like taking my son on walks, and being around to catch all those silly-but-significant little developmental milestones. But most of all, I like knowing that I'm participating actively in raising him - we've been having dude time together since he was born, something that I hope continues for the rest of my life" (Norton 2013).

Involved fathering may also have positive impacts to organizations. In our own research, we found that the more time fathers spent with their children on a typical day, the more satisfied they were with their jobs and the less likely they were to want to leave their organizations (Ladge et al. 2015). Greater involvement was also associated with less work-family conflict and greater work-family enrichment for these fathers. In another study, we found that new fathers can benefit interpersonally at work with colleagues viewing them as more mature and serious, but with a softer side, once they become parents (Humberd et al. 2015). Recognizing fathers as involved parents can build camaraderie and support amongst working parents in organizations more broadly.

Given these positive outcomes, work-family support in organizations has become less about organizations solely supporting mothers, and more about considering how to help all workers in organizations thrive in their work and family lives through both policy reform and informal support (Harrington and Ladge 2009); Kelly et al. 2008). When fathers have access to and feel they can utilize workplace flexibility policies, they report increased job satisfaction, productivity and organizational commitment, and report having better relationships with their co-workers (Bowers 2014). These shifts may be attributed in particular to Millennial generation fathers in the workplace, who report a stronger desire than any other generation to be more involved with their children, viewing their fathering role as a combination of both breadwinner and caregiver (Harrington and Fraone 2016).

Even with these promising shifts, there are open questions as to what constitutes involvement. Many studies that track the household division of labor in families combine all aspects of childcare and housework, making it difficult to assess which aspects of fatherhood men spend the most time engaging in (Bulanda 2004). Further, there may be gender differences in terms of the type of involvement men have with their children, as compared to women, with fathers engaging in "play" with their children, while mothers are often focused on the caretaking and nurturing aspects of parenting (Lamb 2004). Some research finds that when fathers have less traditional attitudes about gender roles, they are more involved in a wide breadth of interactions with their children including leisure activities away from the home, working on projects, helping with homework or playing, having one-on-one conversations and watching television (Bulanda 2004). These complexities lend to questions about the boundaries of fathers' involvement, and potential downsides that can arise from expectations of involvement. 


\subsection{The Downside of Involved Fathering}

While the above discussion certainly recognizes the positive aspects of involved fathering, fathers in dual career couples still face similar work-family balance challenges that mothers face, such as "always feeling rushed" (Livingston and Parker 2019) and never feeling fully engaged in either domain (Humberd et al. 2015). Unlike mothers however, men have fewer role models to look to for support and guidance on balancing work and family (Ladge and Greenberg 2019), and fathers may be less likely to express their desires for involvement fear of being seen as less of an ideal worker or less of a man (Behson 2013). Even though workplace flexibility are purported to be available for all employees, most managers and employees still associate these benefits with women more so than with men, contributing to beliefs that men will not need to adapt their careers to manage family as much as women (Burnett et al. 2011).

When fathers do make use of flexible work arrangements, they face a greater "flexibility stigma" - an informal penalty resulting from perceptions that one is uncommitted to their work if they make use of such arrangements - than women (Williams et al. 2016). Working fathers may even "fake" their hours to manage their needed flexibility while still appearing as a committed worker (Reid 2015); yet in doing so, these men may feel less authentic, and subsequently less engaged in their work. In some ways, it's a difficult dilemma for working dads in organizations: if they make use of the work-family benefits available to them, they are seen as uncommitted, yet if they manage their flexibility in stealth ways, they feel less engaged and perhaps are less productive with their work. Some men have fought against these biases by protesting unequal treatment and taking legal action against their employers (Levs 2015; Johnston 2018), with over a quarter of child-care related discrimination cases filed by men in the past decade (Calvert 2016).

While workplaces may espouse to be receptive to men's role as fathers, many organizations do not actually support these men in being active and involved caregivers, particularly as it relates to paternity leave. In the United States, only $12 \%$ of private sector employees have access to paid parental leave (U.S. Department of Labor 2015) and when it is offered, it is typically short, unpaid, or requires the use of vacation and sick time. Although the number of companies offering paternity leave has increased in the past decade (Harrington et al. 2014; Livingston 2014b), most American fathers still return to work within 2 weeks of their child's birth (Harrington et al. 2014) and many choose to not even use any paternity leave at all, even when they have access to it (Williams 2013). Some research suggests that men may experience biases that can lead to decreased earnings when they do take paternity leave (Rege and Solli 2013), so it is not surprising that many fathers who do have access to leave say that they do not make use of such policies due to informal norms and workplace pressures in their organizations (Harrington et al. 2014). While maternity leave has become a generally accepted option for women, many organizations (including managers, and colleagues of the employees) still do not expect fathers to take leave; doing so, violates implicit norms 
of masculinity, leaving men unable to benefit from any policies that may actually be offered to them.

Together, these norms and social pressures can result in longer-term career consequences for men who want to be involved dads, such as being passed up for promotions and depressed earnings (Coltrane et al. 2013), more harassment and general mistreatment (Berdahl and Moon 2013), and overall perceptions that they are uncommitted to their work (Behson 2013).

\section{Reconciling the Old and New: Redefining Fatherhood}

The picture for working fathers today is complex. Involved fathering is perhaps more accepted and encouraged today than ever before, yet the fatherhood role is still associated with the work domain more so than the family domain. Men face such high expectations of the type of fathers they should be, that it is hard to tell if it is even possible to reconcile these complexities in practice. Likewise, some argue that the father's role in a family has in fact not changed much at all (Wall and Arnold 2007), while other work suggests that fathers are taking on more family and childcare responsibilities in dual-income households (Parker et al. 2017). Further, fathers may perform specific tasks (e.g., watching children at a sporting event or assisting them with technologies) that are a unique form of involvement than is typically assessed or captured (Parker et al. 2017).

Given these variations in how involved fathering is understood and assessed, men themselves may be confused as to how best to reconcile these old and new fathering expectations. Fathers may receive more praise than women for completing ordinary parenting tasks, but face biases at work when adjusting their work to accommodate their family life (Coltrane et al. 2013; Rudman and Mescher 2013). Our own research findings about the positive workplace outcomes associated with involved fathering suggest that there may be an "optimal" amount of time that allows for such benefits to arise: In our study, fathers spent an average of only $2.5 \mathrm{~h}$ with their children during a typical work day (Ladge et al. 2015). A New York Times article aptly stated: "the power of expectations sheds light on why employers reward fatherhood-but only if they don't think men are spending too much time on it" (Cain Miller 2014). Further, even if men espouse a more involved fatherhood, their actual practices often diverge from such notions (Hochschild 1989). A key finding of study we collaborated on found that "while fathers believe that caregiving should be divided equally, they acknowledge that this is not the current reality in their families" (Harrington et al. 2011; Ladge et al. 2015).

There is no question that competing views of fathering exist, and men in professional careers in particular are likely to experience tension around these conflicting expectations. Although fathers may be expected to be more involved in caregiving in the home, images of the ideal, devoted worker are still entrenched in our broader societal expectations and institutional arrangements (Gerson 2009), creating multiple, and seemingly conflicting, expectations of what it means to be a 
father (Humberd et al. 2015). Our research has found that men don't necessarily hold one image of themselves as fathers but instead hold multiple images of themselves as fathers that are sustained through norms and expectations in their day-to-day work and personal contexts. In a qualitative study of 31 first time fathers, our analysis revealed that participants express several different images of themselves as fathers, which represent the various internalized meanings and expectations they hold of how they view themselves and hope to be viewed by others as fathers. The meanings coalesced around four common fathering images - provider, role model, partner, and nurturer - that comprise the content of their fathering identities (Humberd et al. 2015). As these images span from more traditional to more involved notions of fathering, men in our study seemed to maintain the multiplicity of meanings.

Not surprisingly, men express confusion and ambivalence around how to enact their fathering role while trying to preserve an appropriate work image (Reid 2015). For example, outside of work, fathers may emphasize their involvement to increase other's perceptions of kindness and compassion for working dads (Richards 2014), while downplaying their caregiving role at work in order to seem committed to their careers. This confusion and ambivalence has cross-domain effects such that men may adopt a work-family image that may or may not align with their actual identity (Ladge and Little 2019). Thus, even if more involved fathering may be the expected standard today (Ladge et al. 2016), there is little empirical evidence that men are able to truly enact these new expectations in their day to day lives across work and home domains (Coltrane 1997; Gregory and Milner 2011; LaRossa 1988).

\section{Where Can We Go from Here? Bolstering Paternal Competence at Work and at Home}

When referring to mothers, we don't add the term "involved" as we do with fathers for mothers, involvement is implied, yet for fathers, it has to be assessed. In applying that term, it assumes that there is variation in the extent to which fathers should focus on their child(ren). The question then becomes, how do we get to the point where involvement is implied for fathers and not something that needs to be evaluated or speculated? Can expectations of fathers change so that we always assume they are competent, dedicated parents, just in the same way we see them as competent and dedicated professionals? Much research and practical advice considers how women should deal with the guilt that may be associated with being a working mother and build confidence in their abilities to have both a successful career and family life (e.g., Holcomb 2000; Sandberg 2013; Ladge and Greenberg 2019). Similar conversations to guide working fathers toward building a sense of confidence across both domains is necessary; yet this research needs to take into account multiple areas that we consider below.

First, while research is beginning to explore what men can do to manage work and family effectively, there is a need to also examine what women, and couples 
together, can do to support involved fathering in their everyday lives. Recent research has considered the negotiations that spousal couples engage in to decide whose career takes priority (Livingston 2014a) as well as how partners in dual-career couples shape each other's professional identities (Petriglieri and Obodaru 2018). How can we build on these lines of work to truly consider the couple as a unit engaging in the work and home domains? There is much room truly understand the intersections between each partners' sense of confidence and competence in work and home domains. In our own research, we find that fostering new mothers' maternal confidence is important to their experiences of work-family conflict, and ultimately their ability to stay in the workforce (Ladge et al. 2018); but, what does this say about fostering men's paternal confidence? Perhaps part of mothers' ability to build their own sense of confidence in managing work and family could be supported by also recognizing that men need to build similar sense of confidence. It may also be useful to consider the confidence and competence of the parental unit together. Focusing on the parental unit more broadly could also help to move away from dividing gender and further reinforcing traditional norms.

Secondly, future research must also focus on the complexity of family structures that exist today, because understanding what constitutes involvement will differ greatly for different types of families. Indeed, much of the existing literature draws from samples of upper middle class, white fathers in traditional family structures. Some work has begun to acknowledge the different challenges facing fathers in dualcareer couples compared to couples with stay-at-home spouses (e.g., Hammer et al. 1997), or men in heterosexual marriages compared men in gay marriages (e.g., Richardson et al. 2012). There are even more complexities to understand with respect to involvement for fathers with one child, fathers with multiple children, single fathers, widowed fathers, and other increasingly complex and diverse family structures. Similarly, more research can focus on the challenges of involvement across the life cycle of parenting; while current conversations focused on paternity leave are important, we must also extend our research to understand what involved fathering means at middle and later stages of parenting.

Lastly, beyond a focus on the men themselves, more research should consider specifically what can be done within work domains to shift the narrative on what fathering means today. While organizations are seemingly more friendly to working parents today, perhaps the biggest impediment for working fathers is the informal culture in many organizations. Indeed, much research discusses the difficulty in "dislodging the norm of the ideal worker who receives backstage support of a stayat-home wife" (Williams et al. 2013:210). One way to shift the informal culture is having managers and leaders that are "vocal, consistent, and transparent about support for men's caregiving responsibilities" (Humberd et al. 2015:264). Beyond simply support, though, research suggests that leaders need to model behavior (e.g., a CEO that enacts "involved fathering" freely and openly) that opens up the space for all employees to engage in their work and home lives (e.g., Burke and Major 2014; Litano et al. 2014). Thus, leaders who are working parents can play an important role in changing the culture by demonstrating support and acting as role models by utilizing family-friendly practices, talking openly about their own experiences 
managing work and family demands, and encouraging others to do the same. Further, organizations that offer various levels of support for working mothers such as affinity groups and individualized coaching, should offer and encourage the same so that fathers also have the space to participate in discussions about workfamily needs. Additionally, organizations may need to take further steps to enforce policies in order to shift the cultural norms: A recent Wall Street Journal article highlighted some organizations that have begun enforcing a mandatory paternity leave for fathers in their organizations (Lipman 2018). Multiple approaches will be necessary to change taken-for-granted performance expectations and cultural norms that support the view of ideal workers as those that are always present and available.

\section{Concluding Thoughts}

Changes in families have been precipitating changes in the workplace for decades now. While we have paid important attention to the shifts necessary to support working mothers, we owe similar focus to the shifts necessary to support working fathers. Fathers today face similar challenges in managing work and family, albeit often in unexpected or alternative ways from mothers. Without attention to the pressures on both men and women, as well as on the parental unit as a whole - in whatever complex and unique form it comes - we run the risk of reinforcing the long-standing gendered expectations that underpin both work and home domains.

\section{References}

Allen TD (2001) Family-supportive work environments: the role of organizational perceptions. J Vocat Behav 58(3):414-435

Allen SM, Hawkins AJ (1999) Maternal gatekeeping: Mothers' beliefs and behaviors that inhibit greater father involvement in family work. J Marriage Fam 61(1):199-212

Behson S (2013) What's a working dad to do? Harvard Business Review. https://hbr.org/2013/08/ whats-a-working-dad-to-do. Accessed Aug 2021

Berdahl JL, Moon SH (2013) Workplace mistreatment of middle class workers based on sex, parenthood, and caregiving. J Soc Issues 69(2):341-366

Bowers K (2014) A mother's work: special report. Working Mother. April-May 2014 Z(Issue 32) https://www.workingmother.com/special-report/mothers-work-special-report

Bulanda RE (2004) Paternal involvement with children: the influence of gender ideologies. J Marriage Fam 66(1):40-45

Burke RJ, Major DA (eds) (2014) Gender in organizations: are men allies or adversaries to women s career advancement? Edward Elgar Publishing, Cheltenham

Burnett S, Gatrell C, Cooper C, Sparrow P (2011) Fatherhood and flexible working: a contradiction in terms? In: Kaiser S, Ringlstetter MJ, Eikhof DR, Cunha MPE (eds) Creating balance? International perspectives on the work-life integration of professionals. Springer, Berlin, pp $157-172$

Cabrera N, Tamis-LeMonda CS, Bradley RH, Hofferth S, Lamb ME (2000) Fatherhood in the twenty-first century. Child Dev 71(1):127-136 
Cain Miller C (2014) Being a father is good for your career, but don't get carried away. In: The Upshot, New York Times. https://www.nytimes.com/2014/11/14/upshot/being-a-father-isgood-for-your-career-but-dont-get-carried-away.html. Accessed Nov 13

Cain Miller C (2018) The relentlessness of modern parenting. The Upshot, New York Times. https://www.nytimes.com/2018/12/25/upshot/the-relentlessness-of-modern-parenting.html. Accessed Dec 25

Calvert CT (2016) Caregivers in the workplace: family responsibilities discrimination litigation update. Center for Work Life law, University of California - Hastings

Carolla A (2016) Daddy Stop Talking. Dey Street Books, New York

Coltrane S (1997) Family man: fatherhood, housework, and gender equity. Oxford University Press, New York

Coltrane S, Ishii-Kuntz M (1992) Men's housework: a life course perspective. J Marriage Fam 54 (1):43-57

Coltrane S, Miller EC, DeHaan T, Stewart L (2013) Fathers and the flexibility stigma. J Soc Issues 69(2):279-302

Coontz S (1997) The way we really are: coming to terms with America's changing families. Basic Books, New York

Coontz S (2009) Sharing the load. In The Shriver report: a woman's nation changes everything. New York: Free Press. http://shriverreport.org/sharing-the-load/

Coontz S (2016) Gender equality and economic inequality: impact on marriage. In: McHale SM, King V, Van Hook J, Booth A (eds) Gender and couple relationships. Springer, New York, pp 29-90

Cooper M (2000) Being the 'go-to guy': fatherhood, masculinity, and the Organization of Work in Silicon Valley. Qual Sociol 23(4):379-405

Dahl MS, Dezsô CL, Ross DG (2012) Fatherhood and managerial style: how a male CEO's children affect the wages of his employees. Adm Sci Q 57(4):669-693

Deutsch FM (1999) Halving it all: how equally shared parenting works. Harvard University Press, Cambridge

Deutsch FM, Lussier JB, Servis LJ (1993) Husbands at home: predictors of paternal participation in childcare and housework. J Pers Soc Psychol 65(6):1154-1166

Dowd NE (2003) Redefining fatherhood. New York University Press, New York

Furstenberg FF Jr, Harris KM (1993) When fathers matter/why fathers matter: the impact of paternal involvement on the offspring of adolescent mothers. In: Lawson A, Rhode DL (eds) The politics of pregnancy: adolescent sexuality and public policy. Yale University Press, New Haven, pp 189-215. https://repository.upenn.edu/cgi/viewcontent.cgi?article=1042\& context=sociology_papers

Gerson K (2009) Changing lives, resistant institutions: a new generation negotiates gender, work, and family change. Sociol Forum 24(4):735-753

Glass J (1998) Gender liberation, economic squeeze, or fear of strangers: why fathers provide infant Care in Dual-Earner Families. J Marriage Fam 60:821-834

Gregory A, Milner S (2011) What is 'new' about fatherhood? The social construction of fatherhood in France and the UK. Men Masculinities 14(5):588-606

Griswold RL (1993) Fatherhood in America: a history. Basic Books, New York

Hammer LB, Allen E, Grigsby TD (1997) Work-family conflict in dual-earner couples: withinindividual and crossover effects of work and family. J Vocat Behav 50(2):185-203

Harrington B, Fraone JS (2016) The new Millenial dad: understanding the paradox of Today's fathers. Boston College Center for Work and Family, Chestnut Hill

Harrington B, Ladge JJ (2009) Work-life integration: present dynamics and future directions for organizations. Organ Dyn 38(2):148-157

Harrington B, Van Deusen F, Fraone JS, Eddy S, Hass L (2014) The new dad: take your leave. Boston College Center for Work and Family, Chestnut Hill

Harrington B, Van Deusen F, Humberd B (2011) The new dad: caring, committed and conflicted. Boston College Center for Work and Family, Chestnut Hill 
Hochschild AR (1989) The second shift: working parents and the revolution at home. Penguin, New York

Hodges MJ, Budig MJ (2010) Who gets the daddy Bonus? Organizational hegemonic masculinity and the impact of fatherhood on earnings. Gend Soc 24(6):717-745

Holcomb B (2000) Not guilty!: the good news for working mothers. Simon and Schuster, New York

Humberd BK, Ladge JJ, Harrington B (2015) The 'new' dad: navigating fathering identity within organizational contexts. J Bus Psychol 30(2):249-266

Johnston K (2018) More fathers are protesting unequal treatment at work. Boston Globe. https:// www.bostonglobe.com/business/2018/01/02/more-fathers-are-protesting-unequal-treatmentwork/TwmdCd60XyvETvwIX7jDUN/story.html. Accessed Jan 2017

Kelly EL, Kossek EE, Hammer LB, Durham M, Bray J, Chermack K, Murphy LA, Daskubar D (2008) Getting there from here: research on the effects of work-family initiatives on workfamily conflict and business outcomes. Acad Manag Ann 2:305-349

Killewald A (2013) A reconsideration of the fatherhood premium: marriage, Coresidence, biology, and fathers' wages. Am Sociol Rev 78(1):96-116

Kossek EE, Lautsch BA (2018) Work-life flexibility for whom? Occupational status and work-life inequality in upper middle, and lower level jobs. Acad Manag Ann 12(1):5-36

Ladge J, Greenberg D (2019) Maternal optimism: forging a positive path through work and motherhood. Oxford University Press, New York

Ladge JJ, Humberd BK, Eddleston KA (2018) Retaining professionally employed new mothers: the importance of maternal confidence and workplace support to their intent to stay. Hum Resour Manag 57(4):883-900

Ladge JJ, Humberd BK, McNett J (2016) The other half: views of fatherhood in organizations. In: Matthews R, Spitzmueller C (eds) Perspectives on work and the transition to motherhood. Springer Books, Berlin, pp 267-285

Ladge JJ, Humberd BK, Watkins MB, Harrington B (2015) Updating the organization MAN: an examination of involved fathering in the workplace. Acad Manag Perspect 29(1):152-171

Ladge J, Little LM (2019) When expectations become reality: work-family image management and identity adaptation. Acad Manag Rev 44(1):17-40

Lamb ME (2004) The role of the father in child development. Wiley, New York

LaRossa R (1988) Fatherhood and social change. Fam Relat 37(4):451-458

Levs J (2015) All in: how our work-first culture fails dads, families, and businesses--and how we can fix it together. HarperCollins, New York

Lipman J (2018) Want equality? Make new dads stay home: mandatory paternity leave would help close the wage gap and strengthen family bonds. Wall Street J. https://www.wsj.com/articles/ want-equality-make-new-dads-stay-home-1538151219

Litano ML, Myers DP, Major DA (2014) How can men and women be allies in achieving workfamily balance? The role of coping in facilitating positive crossover. In: Burke RJ, Major DA (eds) Gender in organizations: are men allies or adversaries to women's career advancement. Edward Elgar, Cheltenham, pp 365-384

Livingston BA (2014a) Bargaining behind the scenes: spousal negotiation, labor, and work-family burnout. J Manag 40(4):949-977

Livingston $\mathrm{G}$ (2014b) Growing number of dads home with the kids: biggest increase among those caring for family. Pew Social and Demographic Trends. Pew Research Center. http://www. pewsocialtrends.org/2014/06/05/growing-number-of-dads-home-with-the-kids/

Livingston G, Parker K (2019) 8 facts about American dads. Pew Research Center, Fact Tank: News in the Numbers. https://www.pewresearch.org/fact-tank/2019/06/12/fathers-day-facts/

Marsiglio W, Amato P, Day RD, Lamb ME (2000) Scholarship on fatherhood in the 1990s and beyond. J Marriage Fam 62:1173-1191

Masterson CR, Hoobler JM (2015) Care and career: a family identity-based typology of dual-earner couples. J Organ Behav 36(1):75-93

Nathanson P, Young KK (2006) Legalizing misandry: from public shame to systemic discrimination against men. McGill-Queen's Press, Montreal 
Norton J (2013) I'm a dad, not a hero: Thoughts on tom Stocky's Facebook post. Family: modern parenthood, blog, Christian Science Monitor. July 12. https://www.csmonitor.com/The-Culture/ Family/Modern-Parenthood/2013/0712/I-m-a-dad-not-a-hero-Thoughts-on-Tom-Stocky-sFacebook-post

O'Brien M, Shemilt I (2003) Working fathers: earning and caring. Equal Opportunities Commission, London. http://www.fatherhoodinstitute.org/uploads/publications/280.pdf

OECD (2017) How's life? 2017: measuring Well-being. OECD Publishing, Paris. https://doi.org/ 10.1787/how_life-2017-en

Parker K, Horowitz JM, Stepler R (2017) On gender differences, no consensus on nature vs. Nurture: Americans say society places a higher premium on masculinity than on femininity. Pew Social Trends. Pew Research Center. http://www.pewsocialtrends.org/2017/12/ 05/on-gender-differences-no-consensus-on-nature-vs-nurture/

Petriglieri J, Obodaru O (2018) Secure-base relationships as drivers of professional identity development in dual-career couples. Adm Sci Q 27:1-43

Pleck JH (1997) Paternal involvement: levels, sources, and consequences. In: Lamb ME (ed) The role of the father in child development. Wiley, New York, pp 66-103

Pleck EH (2004) Two dimensions of fatherhood: a history of the good dad-bad dad complex. In: Lamb ME (ed) The role of the father in child development, 4th edn. Wiley, New York, pp 32-57

Rege M, Solli IF (2013) The impact of paternity leave on fathers future earnings. Demography 50 (6):2255-2277

Reid E (2015) Embracing, passing, revealing, and the ideal worker image: how people navigate expected and experienced professional identities. Organ Sci 26(4):997-1017

Richards D (2014) Daddy Doin' work: empowering mothers to evolve fatherhood. Jollyfish Press, Provo

Richardson HB, Moyer AM, Goldberg AE (2012) 'You try to be superman and you don't have to be': gay adoptive Fathers' challenges and tensions in balancing work and family. Fathering 10 (3):314-337

Rudman LA, Mescher K (2013) Penalizing men who request a family leave: is flexibility stigma a femininity stigma? J Soc Issues 69(2):322-340

Sandberg S (2013) Lean in: women, work, and the will to Lead. Alfred A. Knopf, New York

Shockley KM, Allen TD (2018) It's not what I expected: the association between dual-earner Couples' met expectations for the division of paid and family labor and Well-being. J Vocat Behav 104:240-260

U.S. Department of Labor (2015) DOL factsheet: paid family and medical leave. https://www.dol. gov/wb/resources/paid_leave_fact_sheet.pdf

Wall G, Arnold S (2007) How involved is involved fathering? An exploration of the Contemporary culture of fatherhood. Gend Soc 21(4):508-527

Weber L (2013) Why dads don't take paternity leave: more companies offer new fathers paid time off, but many fear losing face back at the office. Wall Street J. https://www.wsj.com/articles/ SB10001424127887324049504578541633708283670

Williams JC (2001) Unbending gender: why work and family conflict and what to do about it. Oxford University Press, New York

Williams M (2013) 40\% of fathers do not to take paternity leave. The Guardian News and Media January 06. https://www.theguardian.com/careers/fathers-choose-not-to-take-paternity-leave

Williams JC, Berdahl JL, Vandello JA (2016) Beyond work-life 'integration'. Annu Rev Psychol 67:515-539

Williams JC, Blair-Loy M, Berdahl JL (2013) Cultural schemas, social class, and the flexibility stigma. J Soc Issues 69(2):209-234

Yeung WJ, Sandberg JF, Davis-Kean PE, Hofferth SL (2001) Children's time with fathers in intact families. J Marriage Fam 63(1):136-154 
Open Access This chapter is licensed under the terms of the Creative Commons Attribution 4.0 International License (http://creativecommons.org/licenses/by/4.0/), which permits use, sharing, adaptation, distribution and reproduction in any medium or format, as long as you give appropriate credit to the original author(s) and the source, provide a link to the Creative Commons license and indicate if changes were made.

The images or other third party material in this chapter are included in the chapter's Creative Commons license, unless indicated otherwise in a credit line to the material. If material is not included in the chapter's Creative Commons license and your intended use is not permitted by statutory regulation or exceeds the permitted use, you will need to obtain permission directly from the copyright holder. 